\title{
Natura@economía
}

ISSN 2226-9479 (Versión electrónica)

Website: http://revistas.lamolina.edu.pe/index.php/neu

\section{Abono Orgánico Acelerado: Una alternativa productiva en Hualquín Grande}

\author{
Accelerated Organic Fertilizer: A productive alternative in Hualquín Grande
}

Quispe, M. ${ }^{1 *}$; Cosme, R. ${ }^{1}$; Reynoso, A. ${ }^{1}$; Adama, E. ${ }^{2}$; Juscamaita, J.2; Buendía, M. ${ }^{1}$

'Instituto Nacional de Innovación Agraria, Lima, Perú. Email: miriamrocioq@gmail.com

${ }^{2}$ Universidad Nacional Agraria La Molina, Lima, Perú.

Recepción: 20/06/2019; Aceptación: 15/12/2019

\section{Resumen}

El objetivo del presente estudio fue evaluar alternativas productivas que generen ingresos económicos elaborando Abono Orgánico Acelerado (AOA) a partir de estiércol vacuno 40\%, melaza (10\%), suero láctico (40\%) y consorcio microbiano generador de ácido láctico $(10 \%)$ en el Anexo Huallquin Grande, Tarma, Junín, Perú. El biofertilizante, denominado "Huallquin Fer", fue financiado con el apoyo del Programa Nacional de Investigación Agraria (PNIA) en alianza estratégica con la universidad Nacional Agraria La Molina (UNALM), con la finalidad de minimizar la contaminación ambiental de la actividad ganadera y de la industria láctea del área en estudio, para el beneficio económico de los productores mediante el aprovechamiento de los insumos generados por la actividad ganadera. Para la comprobación y validación del producto se realizó el análisis químico en el laboratorio de la UNALM; se realizaron trabajos en campos mediante parcelas de comprobación en espinaca, obteniendo buenos resultados. Asimismo, se realizó actividades de promoción para la comercialización del Huallquin Fer en diversas ferias agropecuarias. Incrementando el ingreso económico mensual de la Asociación de Productores Perla Andina de Huallquin Grande.

Palabras clave: abono; orgánico; biofertilizante; vacuno; suero de leche.

\footnotetext{
Abstract

The objective of this study was to evaluate productive alternatives that generate economic income by preparing Accelerated Organic Fertilizer (AOA) from 40\% cow manure, molasses $(10 \%)$, lactic serum $(40 \%)$ and lactic acid generating microbial consortium $(10 \%)$. in the

Forma de citar el artículo: Quispe, M.; Cosme, R.; Reynoso, A.; Adama, E.; Juscamaita, J.; Buendía, M. 2019. Abono Orgánico Acelerado: Una alternativa productiva en Hualquín Grande. Natura@economía 4(2):105111(2019). 
Huallquin Grande Annex, Tarma, Junín, Peru. The biofertilizer, called "Huallquin Fer", was financed with the support of the National Agrarian Research Program (PNIA) in a strategic alliance with the Universidad Nacional Agraria La Molina (UNALM), in order to minimize environmental pollution from livestock activities and of the dairy industry of the area under study, for the economic benefit of the producers through the use of the inputs generated by the livestock activity. For the verification and validation of the product, the chemical analysis was carried out in the UNALM laboratory; Works were carried out in fields using spinach check plots, obtaining good results. Likewise, promotional activities were carried out for the commercialization of the Huallquin Fer in various agricultural fairs. Increasing the monthly income of the Association of Producers Perla Andina de Huallquin Grande.

Keywords: fertilizer; organic; biofertilizer; bovine; buttermilk.

\section{Introducción}

Los suelos de la Región Andina por sus condiciones topográficas están expuestos a procesos erosivos producidos por el agua de lluvia (SAG, 2016), que afecta de manera severa a los sembríos con la pérdida de la capa arable, así como de la materia orgánica (MO), cuya presencia es un indicador de la fertilidad del suelo (Estrada-Herrera et al., 2016). Dentro de las buenas prácticas agrícolas para la protección del suelo están la siembra de pastos cultivados que incluyan gramíneas y leguminosas, y la aplicación de enmiendas orgánicas, como son el compost, estiércol, entre otros. Los pastos ayudan a la retención del suelo y a evitar su pérdida (Plan Municipal de Desarrollo. San Juan Yucuita, Nochixtlán, Oaxaca. 2010).

En los sistemas de producción animal, el nitrógeno no metabolizado por los animales en la producción de proteínas como leche, carne o huevos es excretado en la orina y las heces, luego el nitrógeno es liberado hacia el medio ambiente en forma de amonio durante la descomposición del estiércol a través de la acción de la microflora presente (Gay \& Knowlton, 2009). Se pierden nutrientes que podrían ser aprovechados para la elaboración de abonos orgánicos en lugar de ocasionar impactos ambientales negativos (Peralta-Veran et al., 2016).

Asimismo, los agricultores han mostrado la aceptación de la crianza de ganado bovino por las múltiples bondades que ofrece para la nutrición humana. Sin embargo, el excremento animal acumulado en grandes cantidades ocasiona problemas al medio ambiente, contribuyendo ampliamente a la emisión de metano $\left(\mathrm{CH}_{4}\right)$, dióxido de carbono $\left(\mathrm{CO}_{2}\right)$ y óxido nitroso $\left(\mathrm{N}_{2} \mathrm{O}\right)$ a la atmósfera, produciendo el efecto invernadero con el calentamiento de la superficie terrestre y la destrucción de la capa de ozono (Rivas et al., 2008).

En los últimos años, la concentración de metano es inferior al $\mathrm{CO}_{2}$, pero se están incrementando rápidamente y además posee un efecto 21-30 veces más contaminante con respecto al del $\mathrm{CO}_{2}$. Cada año ingresan a la atmósfera 500 millones de toneladas métricas de metano debido a actividades antropogénicas y fenómenos naturales. A efectos de revertir la contaminación ambiental se han realizado varios estudios. Peralta-Veran et al. (2016), utilizaron excretas de ganado vacuno y consorcio microbiano ácido láctico para obtener y caracterizar un abono orgánico líquido. Martínez et al. (2008), señala que ensilar permite aprovechar el máximo el contenido de nutrimentos de las excretas y se logra el control de patógenos. Además, Botero \& Preston (1987) indica que la fermentación anaerobia en la materia orgánica produce un residuo orgánico con buenas propiedades 
agronómica. El Instituto de Investigación Agraria (INIA, 2008) de Perú indica que, se puede preparar biol, en mangas de plástico o en bidones, por un período de dos a tres meses, tiempo promedio que dura la fermentación. En clima frio dura entre 75 a 90 días, mientras que en un clima cálido dura entre 30 a 45 días.

Por lo expuesto, se aprobó el proyecto de transferencia de tecnología "Alternativas productivas que generen ingresos económicos elaborando Abono Orgánico Acelerado (AOA)", a partir del uso de excretas de vacuno y suero de leche, con el fin de disminuir los costos de producción agraria en la Localidad de Huallquín Grande - Tarma - Junín”. En ese sentido, el objetivo del presente estudio fue evaluar la alternativa productiva que generan ingresos económicos elaborando abonos liquido fermentado o en el Anexo Huallquin Grande al elaborar el Huallquin Fer.

\section{Materiales y métodos}

El presente trabajo de investigación, se desarrolló entre los meses de mayo y octubre del año 2017, en el anexo de Huallquin Grande, distrito de Huaricolca, provincia de Tarma, Región de Junín, Perú (Figura 1 y 2). Ubicada a $3780 \mathrm{msnm}$, con una superficie de $6,67 \mathrm{~km}^{2}$. Huaricolca posee un clima semi-seco templado y frígido, por el sector alto de sus punas presenta un permanente enfriamiento. En el verano son comunes los fuertes vientos y heladas; y constantes lluvias durante el invierno. Su temperatura ambiental anual oscila entre los $13^{\circ}$ y $16^{\circ}$ centígrados, con marcados descensos de temperaturas durante las madrugadas en invierno.

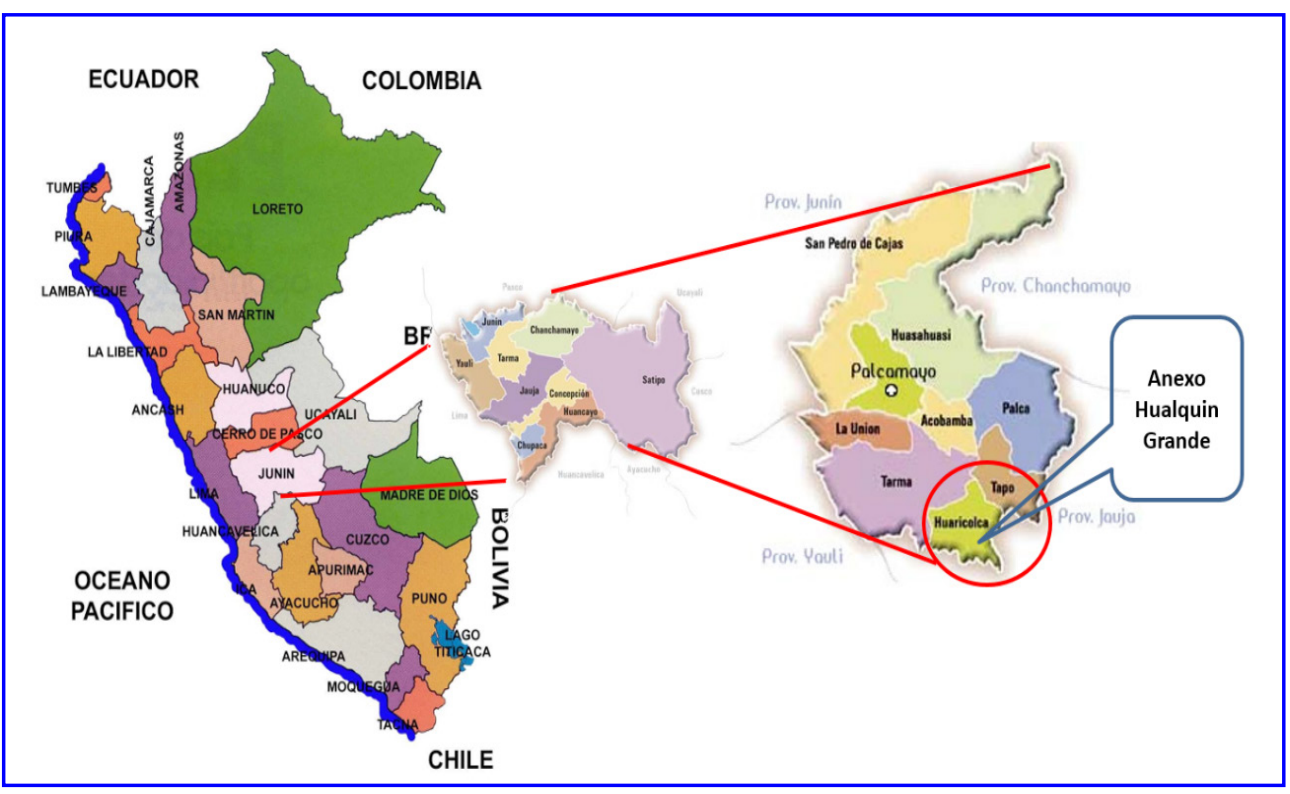

Figura 1: Ubicación del Anexo Hualquín Grande 
En la Figura 2, se detallan las actividades que se realizaron para la elaboración del Abono Orgánico Acelerado. Las materias primas utilizadas fueron: estiércol vacuno $40 \%$, melaza (10\%), suero láctico $(40 \%)$ $\mathrm{y}$ el consorcio microbiano generador de ácido láctico (10\%), denominado Biolac. Mientras que, en la Figura 3 se muestra el Procesamiento del Abono Orgánico Acelerado en la Planta de Producción - Huallquin Grande. La caracterización química del Abono Orgánico Acelerado, se realizó en el Laboratorio de Análisis de Suelos de la Universidad Nacional Agraria La Molina.

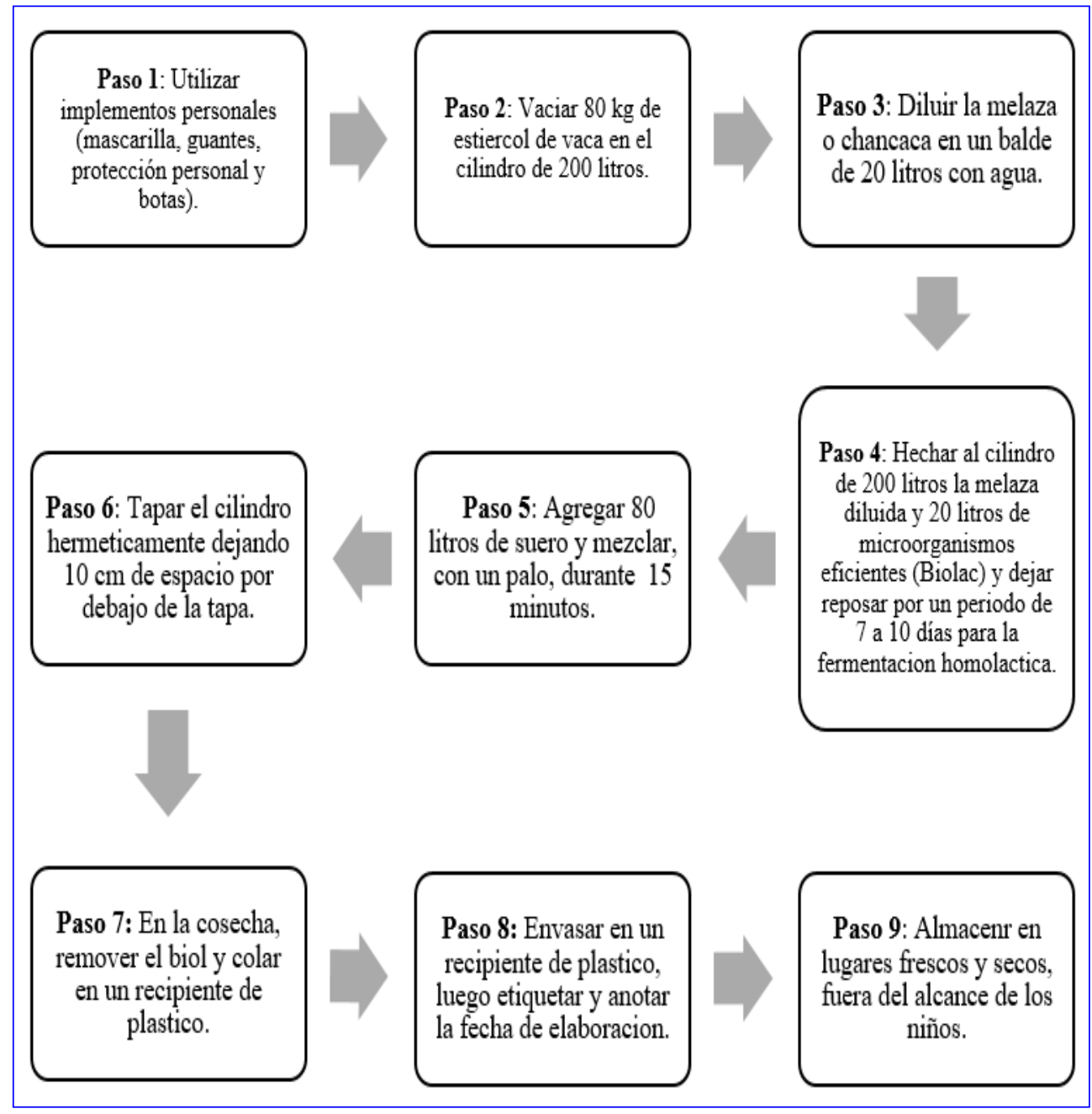

Figura 2: Actividades que se realizan para la elaboración del Abono Orgánico Acelerado 


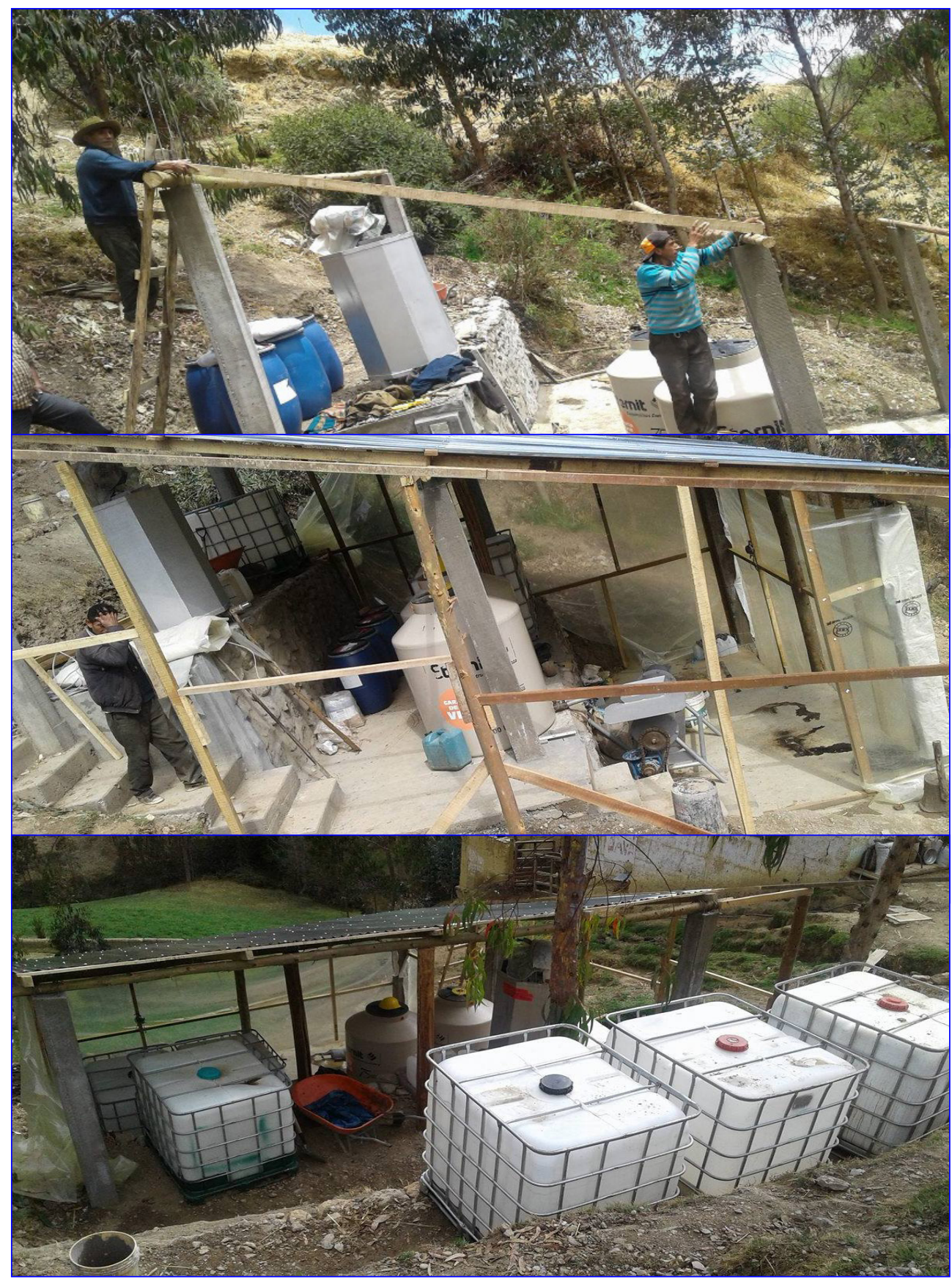

Figura 3: Procesamiento del Abono Orgánico Acelerado en la Planta de Producción - Huallquin Grande, a) Acondicionamiento de la planta de producción, b) Faena en la implementación de la Planta de producción comunidad de Huallquin Grande, y c) Traslado de las canecas y llenado de Suero láctico y recepción de estiércol de vacuno. 
El trabajo de Campo, ha servido para realizar el esquema de la situación actual de la producción de queso del anexo de Huallquin Grande. Para ello, se utilizó diversas herramientas que permiten la obtención de data de forma directa (entrevistas), se trabajó con la muestra y dentro del área de área de estudio.

\section{Resultados y discusión}

En la Tabla 1, muestra la caracterización química del "Huallquin Fer", resultado de la fermentación láctica orgánica, donde se utilizó el consorcio microbiano BioLac. Estas bacterias aceleran el proceso de degradación de los residuos, además de eliminar rápidamente las bacterias perjudiciales y otros patógenos por la producción de ácido láctico, el cual inhibe el crecimiento y desarrollo de bacterias benéficas dándole ventaja competitiva a las bacterias acido-lácticas. Estos ácidos le dan la particularidad a los bioles acelerados de tener un $\mathrm{pH}$ ácido (Peralta, 2010). Según Boucourt et al. (2006) la fermentación disminuye los niveles de E. coli a las $48 \mathrm{~h}$.

Los resultados obtenidos en la Tabla 1 indican aspectos de diferenciación con otros bioles como: no producen gases de efecto invernadero; el ganado vacuno, es alimentado con pastos naturales y cultivados; el suero dulce, es un sub producto de la industria quesera, el ácido láctico actúa como repelente de insectos, controlador de bacterias y hongos; además, contiene mayor proporción de macro y micronutrientes, que son factores de crecimiento (aminoácidos, nucleótidos y vitaminas), bacterias probióticas y no contiene patógenos. El tiempo de elaboración es de siete días, este periodo es menor al reportado por ITDG (2010). Los resultados obtenidos en el abono líquido Fastbiol 20, dieron valores de $<3 \mathrm{NMP} \mathrm{ml}^{-1}$ en coliformes totales y fecales, en un tiempo de 5 días de fermentación anaeróbica.

\section{Conclusiones}

El estiércol vacuno es un residuo de las actividades agropecuarias con alto potencial de ser aprovechado como abono orgánico, al ser utilizado como materia prima en los procesos de fermentación láctica, procesos mediante los cuales se mejoran las concentraciones de sus nutrientes. El proceso de producción del Biol caseros se caracteriza por un largo tiempo de obtención y una variación de $\mathrm{pH}$ entre los valores $6,8-$ 7,8. Por lo contrario, el tiempo de retención para la producción del ALF es de 10 días y la variación del $\mathrm{pH}$ es más amplia hasta alcanzar valores muy ácidos (alrededor de 3,44 ), los cuales se mantienen incluso después de haber transcurrido 30 días de iniciado el proceso. Las concentraciones de nutrientes (N, P, K, Ca, Mg) del ALF son más altas que las de bioles generados a partir de otros residuos agropecuarios como la gallinaza, el estiércol de cuy y el estiércol de porcino.

\section{Agradecimientos}

Los autores agradecen al Programa Nacional de Innovación Agraria (PNIA) por el financiamiento a través del proyecto de transferencia de tecnología 119_PTT "Alternativas productivas que generen ingresos económicos elaborando Abono Orgánico Acelerado (AOA) a partir de

Tabla 1: Comparación de la Caracterización química entre Huallquin Fer y Avibiol

\begin{tabular}{ccccccc}
\hline Producto & $\mathrm{pH}$ & $\begin{array}{c}\text { Nitrógeno total } \\
(\mathrm{mg} / \mathrm{L}\end{array}$ & $\begin{array}{c}\text { Fósforo total } \\
(\mathrm{mg} / \mathrm{L})\end{array}$ & $\begin{array}{c}\text { Potasio total } \\
(\mathrm{mg} / \mathrm{L})\end{array}$ & $\begin{array}{c}\text { Calcio total } \\
(\mathrm{mg} / \mathrm{L})\end{array}$ & $\begin{array}{c}\text { Magnesio total } \\
(\mathrm{mg} / \mathrm{L})\end{array}$ \\
\hline $\begin{array}{c}\text { Huallquin } \\
\text { Fer }\end{array}$ & 3,44 & 2436,0 & 350,89 & 1890,0 & 2947 & 1290 \\
\hline
\end{tabular}


excretas de vacuno y suero de leche, y disminución de costos de producción agraria en la localidad de Huallquin Grande - Tarma - Junín”.

\section{Literatura citada}

Botero R. \& Preston, T. 1987. Biodigestor de bajo costo para la producción de combustible $y$ fertilizante a partir de excretas. Manual para su instalación, operación y utilización. Centro para la Investigación en Sistemas Sostenibles de Producción Agropecuaria (CIPAV), Cali, Colombia. 30p.

Bourcourt R., Carrasco E., López A., Rodríguez Z. \& Gutiérrez, O. 2006. Microbiota aerobia en caña fermentada con excreta vacuna como alternativa alimentaria. Revista Cubana de Ciencia Agrícola, Tomo 40, No 3 pp. 279-281.

Estrada-Herrera, I.; Hidalgo-Moreno, C.; Guzmán-Plazola, R.; Almaraz, J.; Navarro-Garza, H.; Etchevers-Barra, J. 2016. Indicadores de calidad de suelo para evaluar su fertilidad. Agrociencia 51: 813-831. 2017.

INIA (Instituto Nacional de Investigación Agraria). 2008. Folleto Producción y uso del biol. Serie No 2. 1era Edición.

Gay S. \& Knowlton K. 2009. Ammonia Emissions and Animal Agriculture. Virginia Cooperative Extension. Virginia State, USA. pp 1-5

ITDG [Tecnologías desafiando la pobreza]. 2010. Preparación y uso de biol. Disponible en: http://www.funsepa. net/soluciones/pubs/Njc0.pdf

Martínez A., Mendoza G., González S., Gómez A., Estrada M., De la Cruz E., Cruz A., Brito N. \& Pinos J. 2008. Evaluación in vitro de un ensilado de estiércol, rastrojo de maíz y melaza.
Universidad Juárez Autónoma de Tabasco. México. Vol. 24, No 3 pp. 247-250.

SAG [servicio Agrícola y Ganadero]. 2016. Evaluación de Riesgos de activación de procesos erosivos. Disponible en https://www.sag.gob.cl/sites/default/ files/evaluacion_de impactos de riesgos_de_activacion_de_procesos erosivos_vsag.pdf

Peralta-Veran L.; Juscamaita-Morales, J.; Meza-Contreras, V. 2016. Obtención y caracterización de abono orgánico líquido a través del tratamiento de excretas del ganado vacuno de un establo lechero usando un consorcio microbiano ácido láctico. Ecología Aplicada 15(1): 1-10.

Peralta, R. 2010. Determinación de parámetros óptimos en la producción de fast biol usando excretas de ganado lechero del establo de la UNALM. Tesis para optar el título de biólogo, UNALM. Lima, Perú. 120 p.

Plan Municipal de Desarrollo. San Juan Yucuita, Nochixtlán, Oaxaca. 2010. www.elocal.gob.mx/work/templates/ enciclo/ oaxaca/municipios/20224a. htm-19k. (Consulta: noviembre 2016).

Rivas B., Segovia A., Morales H., Hermosillo J. \& Magaña, J. 2008. Plan de gestión para el desarrollo sostenible de explotaciones lecheras de la cuenca de Delicias. Tecnociencia Chihuahua. México. Vol. 2. No 1 pp. 41-56. 